\title{
Primary School Teachers' Perspective on Study and Substantial Fulfilment in South Korea
}

\author{
Hyejin Bak \\ Seoul National University, Republic of Korea
}

\begin{abstract}
This study analyses teachers' perspectives of their own study through field research. The field study location was a primary school in Seoul, South Korea; the research period was from March to May 2015. I collected data based on observations, interviews and field data. Data collection focused on the after-school activities of Year 3 homeroom teachers. This study examines how primary school teachers consider and conduct personal study. Findings show that teachers tend to consider study with respect to concepts of professional development and/or self-enrichment. Most importantly, they show a strong willingness to study voluntarily and actively for their students' benefit based on their experimental situations and school circumstances. This implies that teachers need a better environment and sufficient time, rather than expansive teacher training programmes provided for their own studies and reflection on their own situations, and they should not be pushed to prioritise too many administrative tasks during their time spent at the school.
\end{abstract}

\section{Introduction}

Click, click, click, click.

A teacher is quickly clicking a computer mouse, passing through the screens of an online in-service teacher training programme without retaining any learning since she must complete the 60hour teacher training requirement in a primary school in South Korea.

This hypothetical scene is based on the real state of teacher training programmes.

In-service teacher training programmes are provided and controlled by the Teacher Welfare and Training Division of South Korea's Ministry of Education. These programmes support professional development and quality management based on school units and training institute units in qualification and practical training, and on evaluation and accreditation of training institutions [1]. As these emphases implicate, teacher training programmes could play a significant role in encouraging professional development of teachers who could directly affect the quality of school education for students. Why then do teachers take a negative attitude toward in-service teacher training programmes? It could be a result of the tacit obligation (not legal requirement) for primary school teachers to 'complete' the 60-hour teacher training to avoid being penalised in individual and school evaluations.

Two questions arose about this quasi-duty and teachers' behaviour:

- Aren't teachers able to benefit their students based on their own study plans and activities?

- What does study mean for teachers?

I designed the following research purpose and research questions to address these concerns.

\section{Research purpose}

This research explored how Korean primary school teachers work or study voluntarily in their work places (primary schools) to investigate teachers' perspectives and pursuit of their own study.

\subsection{Research questions}

The main research question to be answered is: 'What does teachers' after-school time consist of?' The following sub-questions are asked:

1) What is the purpose or goal of each teacher activity during after-school time?

2) What connections exist between studies that teachers consider and teachers' activities during after-school time?

3) Are theoretical paradigms of teacher study different from or similar to reality?

Korean primary school teachers normally have about two hours of after-school time after their students leave and before their quitting time. I conducted research of teachers' study during this time because it can be spent relatively flexibly; it is not governed by a fixed schedule.

\section{Research methodology}

\subsection{Research design}

The research field was a primary school comprising 25 classes in Seoul, South Korea. The research's focus participant was a 30-year-old female 
teacher, Jeong, who was certificated as a Korean public primary school teacher in 2011. She was one of Year 3's homeroom teachers. The other four Year 3 homeroom teachers and three additional primary school teachers also participated in the research.

I remained in the field from 2:00 pm until 4:40 pm, Jeong's quitting time, biweekly on Monday and Thursday between the months of March and May 2015. I visited on Thursday to observe the teachers' meeting, which is held during after-school time on that day. During the meeting, in addition to announcement of school events or teacher tasks at the school level by the Year's head teacher, direct mutual exchange of opinions or information and interaction among teachers occurred. Beginning in April, I also visited the field intermittently on Monday to compare after-school time activities with and without the teachers' meeting.

\subsection{Research methods and data collection}

Research data was collected primarily through participant observations. I also conducted one semistructured interview and several interviews via Email and social network systems, beginning from the middle of the research period. E-methods were more useful, but less disturbing, ways to connect with Jeong. Furthermore, once or twice via social network systems I interviewed two primary school teachers who were studying as Master students and a teacher who was working in another primary school. Field data referred to teachers' documents, the school's website, the online administrative system, my field notes and research diary, and so on.

\section{Teachers' after-school time and study}

Before beginning my research, I initially assumed that teachers would address administrative tasks or prepare classes for the next day as a simple pattern of work during after-school time. However, I came to discover various types of teacher activities, and the importance of flexibility in adapting to the participants' environment, such as school or personal situations, on each day and in each period. Moreover, teachers discussed more varied topics than I expected during the homeroom teachers' meeting, which occupied most of after-school time on Thursday. These topics related to the teachers' studies as well as school schedules and events.

\subsection{Implication 1: Meaning of teacher activities during after-school time}

Based on the case of Jeong, I assumed that the meaning of each activity conducted during afterschool time would vary according to the attitudes of the teacher. Activity factors can be divided into voluntary and involuntary categories; all Jeong's work-related activities were involuntary factors (Figure 1: B, D). She was sometimes annoyed or upset by work concerning curriculum, since these tasks were relatively disconnected from teaching and caring for students in the classroom, and the teacher in charge of curriculum required inefficient progress and outcomes (D). However, Jeong showed a consistently positive attitude about work concerning Science Education for talented students, tasks related to special activities for students (B). Jeong spent most of her after-school time on involuntary extra work, which was a difficulty for her. Although educational authorities, teachers, and society emphasise the roles of teachers in students' lives, particularly that of homeroom teachers at the primary school level, teachers find that the actual situation does not provide enough support for these expected roles. It is necessary to carefully determine the most important work that teachers should do during afterschool time, and to discover realistic support for teachers' fulfilment.

\begin{tabular}{|c|l|l|}
\multicolumn{1}{c|}{ Voluntary } & \multicolumn{1}{c|}{ Involuntary } \\
\cline { 2 - 4 } Positive & $\begin{array}{l}\text { - Communication } \\
\text { with students } \\
\text { - Preparation for } \\
\text { classes } \\
\text { - Educational } \\
\text { guidance for } \\
\text { students }\end{array}$ & $\begin{array}{l}\text { Tasks } \\
\text { concerning } \\
\text { education for } \\
\text { scientific talent }\end{array}$ \\
& (A) & (B) \\
\hline & (C) \\
& (D) \\
& $\begin{array}{l}\text { Tasks } \\
\text { concerning } \\
\text { national } \\
\text { curriculum }\end{array}$ \\
\hline
\end{tabular}

Figure 1. Teachers' Attitude about After - School Time Activities
Jeong: I think it is ideal to spend after- school time for preparing classes, counselling students' parents, providing educational guidance to students and so on...because, as a teacher, it is most rewarding to see my students becoming better.

As seen in Figure 1 (A, voluntary/positive tasks), the most meaningful after-school time tasks for teachers are those concerning 'teachers for students' activities. These meaningful tasks relate to the classroom environment in which teachers instruct and nurture students and classes, provide educational 
guidance, and interact with students. For instance, during after-school time, Jeong cleans or decorates her classroom with student artwork. She takes time for self-review of the day's teaching and preparation for upcoming classes.

Teachers consider their students' intellectual, emotional and other developmental levels, and based on these developmental levels, they research suitable moral guidance and communication methods. In Jeong's case, she was especially concerned with these aspects since she was in charge of a low-grade class in the beginning of the year.

\subsection{Implication 2: Connections between teacher's perspective on study and after- school time activities}

This research found that teachers usually describe their study based on concepts of 'professional development' and 'self-enrichment'. These two concepts can either overlap or remain distinctly separated based on a teacher's tendency to place greater significance on study either as 'a teacher based on the occupational aspect', or as 'a learner based on the individual aspect'.

Teachers regard self-enrichment as a type of study if they identify more as an individual person than as the holder of an occupational position; they focus on discovery and development of their potential abilities. From this perspective, personal reasons for study are stronger. Such teachers thus tend to pursue 'self-enrichment' study to learn about their interests or acquire higher degrees from systematic educational institutes. They tend to spend time on their own learning after work, during vacation, or through leaves of absence, instead of during after-school time. They seem to consider the pursuit of higher degrees to be bolder or more challenging missions for self-enrichment. This selfenrichment is additionally deeply involved with 'self-contentment', relating to the social atmosphere that prefers and appreciates a higher educational background.

The term 'professional development', on the other hand, indicates study conducted to ensure better performance in the role of a teacher for students. In this case, teachers consider this an ideal activity for after-school time. This tendency corresponds with the social quest to support high quality in education, teacher education, teacher professional development, and study of teacher preferences. Teachers refer to professional books or shared online resources about teaching and guiding students, and seek plans for practical application of this knowledge. The most common method employed is the use of mutual interaction with other teachers to learn practical and experimental knowledge or skill. In Jeong's school, this cooperative study is implemented most during the teachers' meeting. Early-career teachers in particular tend to rely on experienced teachers. Moreover, beyond simply acquiring knowledge from other teachers, active teachers are also willing to share their own experimental knowledge or resources concerning good teaching, study methods and so on.

The following conversations are parts of a discussion about physical education classes during a meeting with the Year six homeroom teachers.

Kim: Let's arrange games and plays which we can use during physical education classes together. How about tomorrow?

Jang: How about 'platform-dodge ball'? We (teachers) can organise teams in class before going to the gym.

Bae: I think we need to decide on playing time, and draw a small circle with plastic tape on the floor in the gym in advance.

Related to this kind of situation, Jeong says as the following:

Jeong: Other homeroom teachers' advice is really helpful...they can understand kids well because I don't have any experience bringing up children...I am sometimes embarrassed because of my students. So, I ask them for some advice, and they tell me like 'try this way for that case'. Then, I refer to their advice...not only for teaching...[Therefore, before I go to a teachers' meeting], I always think about what I could ask them. Of course I can ask some advice personally, but I can get various opinions from teachers at once. And I can choose a better and more suitable way among many opinions... In terms of teaching, for instance, Jang tried many art methods, like 'tessellation', with her students earlier, and told us (other homeroom teachers) 'it was good', and prepared all materials for us too. That is really good for us.

As in the case of Jeong, teachers consider professional development to involve acquiring practical and experiential knowledge and becoming experts in the field. However, although teachers link 'study' with 'professional development' and 'professional development' with 'acquiring and sharing concrete activities/practical knowledge', they do not directly link 'study' with 'acquiring and sharing concrete activities/practical knowledge'. 
Meanwhile, teachers who regard professional development as related to self-enrichment not only emphasise professional development in the teaching role, but also describe professional development as acquiring the knowledge or skill to more efficiently teach, nurture, or guide students from a training educational centre, not as a learner in the school.

As [Figure 2] shows, Jeong described the concepts of self-enrichment (she considers selfenrichment to be study) and professional development (she did not describe pursuit of better teaching and educational guidance as 'study') as distinct. However, she said she would like to take a Master's course in child psychology and counselling, which would offer her both professional development and new professional knowledge she could apply in practise. This indicates that Jeong in fact does think of study as both self-enrichment and professional development, without consciously recognising the overlap.

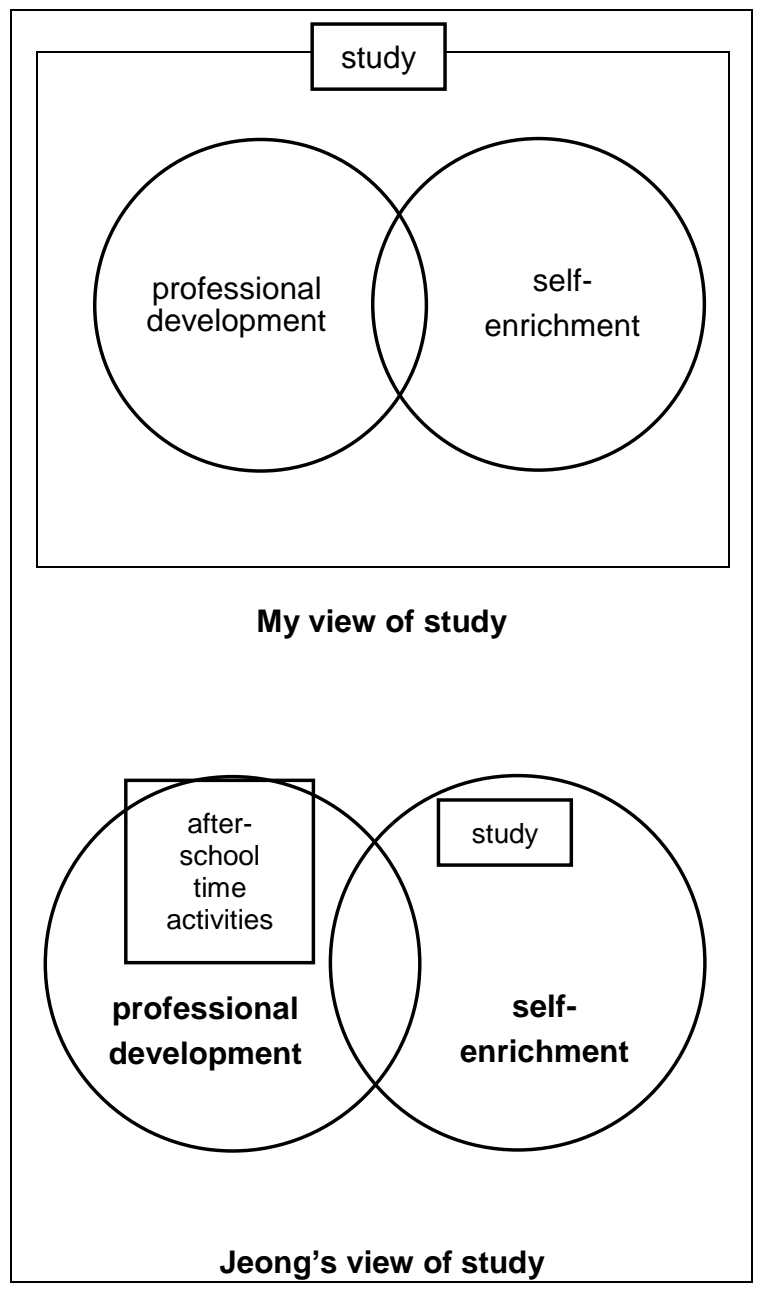

Figure 2. Perspectives on study

\subsection{Application 1: Theoretical paradigms and reality of teacher study}

Jeong is a qualified public primary school teacher who passed the Teacher Employment Examination administered by the South Korean government. The content of the mainstream curriculum is based on government-designated textbooks, and plans for periods and class times are coordinated based on the school's specific curriculum and the national standard curriculum. In this context, Jeong is an 'effective teacher' who demonstrates accountability and capability to foster human resources as a governmental pursuit [2].

However, Jeong does not simply play the role of delivering knowledge; she also tries to seek the most effective teaching-learning methods and resources for her students by considering her class's circumstances and her students' reactions and developmental levels, adapting the learning content at her discretion. She uses more interesting resources by considering class progress based on the standard curriculum. She also reflects on whether students seemed bored or less reactive, and tries to find better teaching-learning methods to overcome this. She carefully considers her expressions, gestures, vocal tones and linguistic habits as well as the content of her teaching, since aspects of the teacher could have an unintended effect on students' intellectual or emotional development. Furthermore, she tries to understand students' developmental levels and communicates with them at their level in order to be a kind and cheerful teacher. Her worries and challenges might be considered 'study' to be a better and more professional teacher. In Jeong we find the attitude of the 'reflective teacher' [3], who tries to go beyond the role of 'effective teacher' through practise and introspection in study [4].

The importance of cooperative reflection and practical research among teachers is emphasised in development of the professionalism [5], [6]. I found evidence of teacher cooperation, for example when teachers adapt the advice or help of experienced colleagues, in Jeong's case as well. If Jeong simply accepted the experiences of other teachers without critical consideration, it would not be reflective practise. Instead, she selects options from among the advice given and adapts these options with regard for her students' levels or circumstances. I therefore deduce that she has reflective attitudes.

However, Jeong is hesitant to share her own ideas or plans concerning teaching-learning methods or educational guidance. She neither conducts systematic research about her cases or experiences, nor participates in teacher research communities. She seems somewhat uninterested in those activities. Additionally, she does not link her role as a teacher to social change or engagement. I thus call her case that of a 'passive' reflective teacher. The passive 
reflective attitude demonstrated by Jeong might be a result of less practical field experience as an early career teacher, as well as feelings of insufficiency, pressure and cautiousness (due to Confucian values) in her position as a junior teacher 20 years younger than the senior homeroom teachers in their 40s and 50 s, even though they are supportive rather than exacting.

\subsection{Application 2: Cooperative reflection and practical research among teachers}

In South Korean primary schools, teachers take charge of different grades each year, allowing them the opportunity to experience teaching in all grades, from first to sixth, and to understand the distinct characteristics of each grade over the course of a 10year career. Another feature of South Korean PT society is that homeroom teachers of the same grade tend to associate or interact more with one another.

Teachers, especially early-career teachers, could study more active 'reflection' and 'practise' and promote greater professional development by making the best use of their senior colleagues and a cooperative and supportive environment, beyond simply acquiring knowledge from other teachers who are willing to share their knowledge and resources.

Therefore, the importance of cooperative reflection and practical research among teachers is emphasised to develop professionalism.

\subsection{Application 3: Professionalism and reflective study in the perspective of teachers}

Educational authorities provide a broad range of teacher training programmes and goals, and they expect teachers to develop their professionalism through these training programmes according to fixed administrative goals and directions. In reality, however, teachers focus more on study for professional work in their practical field, since they most value their direct roles as teachers of students. They consider this to be 'teacher's professionalism' and work to develop it.

Essentially, teachers tend to consider professional development an important factor that should be accomplished practically in the school. They want to increase practical professionalism and to learn concrete professional knowledge and skill for real situations. Therefore, they try to build practical professionalism through direct interaction with students during school, and they reflect and study independently during after-school time. Teacher study is conducted with respect to their individual circumstances and environmental factors, using online resources or other teachers they can 'access' within the school.

In summary, teacher study is a form of 'reflective study' that is feasible, practical, and contextual, despite a lack of systematic organisation, normalisation and planning.

\section{Conclusion and suggestions}

This research considered the relation between teachers' perspectives on study and activities conducted during after-school time. I will be delighted if this research proves helpful in understanding how seriously teachers take their roles, how hard they work, how much they consider their students and what they need to properly fulfil their roles.

Teachers' voices should be heard to improve their working conditions and accommodate voluntary and active study. Teachers must be given enough time to act as 'a teacher for students', rather than pushed to work as 'a worker for the organisation'. Moreover, in-service teacher training programmes that teachers can learn and conduct spontaneously would be preferable to perfunctory programmes that merely convey theoretical knowledge.

A final important concern is that teachers themselves should not only try to dismantle social or cultural prejudice concerning teacher laziness or lack of professionalism, but also do their best in their duties and responsibilities.

\section{References}

[1] Ministry of Education, Teacher Welfare and Training Division. (2014) 2015 Teacher Training Programme Plan, Seoul, South Korea.

[2] Kwak, Y. (2014) Teacher and Qualitative Research (교사 그리고 질적연구, self-translated), Kyoyookbook, Paju, South Korea.

[3] Stronach, I., Corbin, B., McNamara, O., Stark, S. \& Warne, T. (2002) 'Towards an uncertain politics of professionalism: teacher and nurse identities in flux', Journal of Education Policy, 17 (1), pp. 109-138.

[4] Kwak, Y. (2014) Teacher and Qualitative Research (교사 그리고 질적연구, self-translated), Kyoyookbook, Paju, South Korea.

[5] Griffiths, M. \& Tann, S. (1992) 'Using reflective practice to link personal and public theories', Journal of Education for Teaching, 18 (1), pp. 69-84.

[6] Seo, K. (December 2005) 'The Fallacy and Possibilities of Reflective Teacher Education', The Journal of Korean Teacher Education, 22 (3), pp. 307-332. 


\section{Acknowledgements}

Thank you to JEONG, E. and the teachers who helped with this study. A special thank you to professor JO, Y. for his guidance. 